\section{Cliniral oluseruations}

ON

\section{JEJUNO-COLIC FISTULA FOLLOWING GASTRO-JEJUNOSTOMY.}

BY

CHARLES BOLTON, C.B.E., M.D., F.R.S.,

FELLOW OF tHE ROYAL COLLEgE OF PHYSICIANS; PHYSICIAN to UNIVERSITY COLLEGE HOSPITAL;

AND

WILFRED TROTTER, M.S., F.R.C.S.,

SORGEON TO ONIVERSITY COLLEGE HOSPITAL.

That the operation of gastro-jejunostomy is occasionally followed by the formation of a jejunal ulcer is a well established fact. The frequency with which this serious after-result occurs is unknown, but it has been estimated at from 1 to 2 per cent. of operations. The ulcer forms at the anastomosis, from which it commonly spreads in the jejunum, sometimes in the stomach, occasionally in both; or it arises primarily in the jejunum near the anastomosis, but sometimes at a greater or lesser distance from it in the efferent limb. A little over 10 per cent. of jejunal ulcers become adherent to the transverse colon and perforate into it, thus establishing a jejuno-colic fistula, or much less commonly a gastro-colic or. a gastro-jejuno-colic fistula. Four such cases have recently come under our observation, and a reference to the literature shows that there are already twenty-seven cases on record. Most of the cases have naturally been published as isolated observations, but a paper or two have been written on the analysis of such cases, which clearly show that the condition possesses a definite and characteristic, though variable, clinical picture, which is worthy of closer study, particularly as this complication of jastro-jejunostomy has hitherto attracted very little attention in England.

\section{Historical.}

The first case on record was a gastro-colic fistula, which was operated upon by Czerny ${ }^{1}$ and published in 1903 . An ulcer on the anterior wall of the stomach originating at the edge of the gastro.jejunostomy opening had perforated into the transverse colon, which had become adherent to the base of the ulcer. In 1905 von Herczel ${ }^{2}$ published the first operation on a jejuno-colic fistula formed by the perforation of a jejunal ulcer situated in the efferent limb opposite the anastomosis into the transverse colon. In the following year Kaufmann ${ }^{3}$ described a case of his, which was operated on by Gérster and in which there were two fistulae, one between the stomach and colon, and a second between the jejunum and colon. Gosset's ${ }^{4}$ first case was published in the same year, and in 1909. Lion and Moreau ${ }^{5}$ wrote a paper on this subject based on the abovementioned cases and two additional ones, which were operated on by Nélaton and Gosset (second case) respectively. 'They appear to have overlooked a case reported by Port and Reitzenstein ${ }^{6}$ in 1907, in which the fistula connected the colon with the stomach and jejunum.

In a paper on jejunal ulcer Paterson, ${ }^{7}$ in 1909 , quotes four of the abore cases, and in addition a post-mortem examination by Cackovic, in which an unexpected jejunocolic fistula was found opposite the anastomosis. In the following year Van Roojen ${ }^{8}$ also published a communica. tion on jejunal ulcer, and found that of the cases he had collected nine had perforated into the colon. He quoted four cases which have not been mentioned above, namely, those of Van Stockum, Koch, Wickershausen, and von Herczel (second case). In 1913 Polya $^{9}$ described a case and summarized the knowledge obtained up to date on this subject, and quoted the additional cases of Pinner, Sesin, Spassokukozki, Gosset (third case), and two of von Eiselsberg. Since this year a further eight cases have been published. In 1915 Hamann $^{10}$ described the case of a medical man in whom a jejuno-colic fistula was operated on four years after the gastro-enterostomy was performed. Barling, ${ }^{11}$ in 1917, published the case of a man in whom a jejuno-colic fistula was diagnosed three years after gastro-enterostomy. The patient died five months later of general peritonitis due to the perforation of a second jejunal ulcer. At the New York Surgical
Society on April 10th, 1918, Downes ${ }^{12}$ read a paper on the case of a man who first had the appendix removed without benefit, and then a gastro enterostomy performed five months later. The following month a second opera. tion was done for closure of the stoma. Eleven months later an anastomotic ulcer was excised and gastroenterostomy again done. During the following year he had three haemorrhages from the bowel, and was treated medically. Two years later symptoms of fistula appeared, and after two months the fistula was closed and the gastro-enterostomy opening enlarged. The patient was reported well three months later. At the discussion which followed the reading of this paper Erdmann related the case of a male patient of his on whom he had successfully operated for jejuno colic fistula a year previously.

Carnot, Froussard, and De Martel ${ }^{13}$ in 1918 gave a very full and interesting account of their observations on a case which showed definite symptoms of fistula two years after gastro-enterostomy. The parts were resected and end-toend anastomosis of the large and small intestine with closure of the gastro-enterostomy stoma performed. Clairmont ${ }^{14}$ in 1918 showed three cases at the Medical Society of Vienna on whom he had done extensive resections for jejuno-colic fistula. The details of these operations are given in a later paper. ${ }^{15}$

Two further papers, by Mathiew ${ }^{16}$ and Urutia ${ }^{17}$ respectively, have been published on this subject, but we liave been unable to obtain copies of them in London. Thus 27 cases at least have been recorded, and the addition of our 4 cases brings up the total to 31 . No doubt many un. published cases exist. ${ }^{18}$ We shall now give reports of these 4 cases, which were primarily patients of one of us (C. B.). The first three were operated on by the other of us (W. T.), and the fourth case died after a laparotomy by another surgeon had failed to find the cause of the faecal vomiting.

CASE I.-Perforated Duodenal Ulcer : Gastro-jejumostomy (1915) : later Vomiting and Diarrhoea : Operation (1919) for Jejuno. colic Fistula: Temporary Caecostomy : Recovery.

T. G., male, aged 37, railway attendant, was admitted to University College Hospital on March 14th, 1919.

\section{History.}

The symptoms began in 1901 with pain in the right part of the epigastrium under the costal margin, two hours after meals and relieved by food. Sometimes it was a "doubling up " pain, at other times milder. There was fullness in the epigastrium, and eructations of wind and acid tluid; vomiting was rare. These symptoms recurred at intervals in attacks which lasted a few months. In the intervals the patient was quite well. In 1915 the ulcer, which was duodenal, perforated. He was operated on at University College Hospital ; the opening was stitched up on at University College Hospital ; the opening was stitched up and posterior gastro-jejunostomy performed at the same time. griping pain in the lower part of the abdomen, which had continued intermittently ever since, though for the last twelve months it had been less marked, and had recently disappeared. The bowels were regular.

Six months before admission the old pain under the right ribs reappeared. 'It came on, as before, two hours after meals, and was relieved by food, but was not so severe and gniping, and was relieved by food, but was not so severe and gniping, although otherwise of the same character. There were also fullness and eructations of wind. 2 wo months before admiswere ernctated; and a fortnight later he suddenly vomited over a pint of light-coloured very offensive material. A second attack of vomiting occurred two weeks before admission, and as ceded by a sensation of constriction in the upper part of the abdomen. The material was of the same nature as before, but smaller in amount. A third attack occurred the day before smaller in amount. A third attack occurred the day before before, but less than a pint in amount. There was no vomiting in the intervals between these three attacks, but offensive gas and fluid were eructated.

Diarrhcea commenced just before the first attack of vomiting two months ago, the bowels having been quite normal previously. The diarrhoea having once started continued more or less incessantly, occurring any time in the day or night. The stools were light-coloured and contained a little mucns but no blood. They were very similar to the vomited material. blood. They were very similar to the vomited material. chondrium and down the left side. The pain in the epigastrium was dull and aching and radiated downwards over the whole abdomen. It was more or less constant, coming on at an time, and being relieved by food for a time and also by the vomiting. Patient had a severe attack of intestinal colic two weeks before admission. Wasting began with the first attack of vomiting, and during the two months he lost 10 lb. The appetite was moderate and sleep poor. Patient stated that he felt better when the bowels were confined. 
Condition on Admission.

The patient was pale and thin, weighing 8 st. $5 \mathrm{lb} .12 \mathrm{oz}$. He romited on two occasions, bringing up about $6 \mathrm{oz}$. of light-brown coloured liquid material of faecal odour and not containing any solid masses. His symptoms were as described above.

Diarrhoea did not occur on every day, an enema simplex being necessary on two occasions. The stool was light-brown and soupy, did not contain any amount of solid material, and was in appearance like the vomit. It contained 85 per cent. water. The total fats were 18.8 grams per cent. dry weight, the fatty acids and weutral fats being each 9.4 per cent. There were some undigested muscle fibres, but no evidence of either trypsin or starch digesting ferment. There was no lienteric diarrhoea.

A test meal showed a total acidity of 0.1095 gram per cent. There was no free $\mathrm{HCl}$, no lactic acid; the protein $\mathrm{HCl}$ was 0.1095 gram per cent. Albumoses were present, and the digested power of the fluid was 52 per cent.

Physical examination of the ablomen showed a median epigastric scar. There was a tender spot under the right costal margin, but no marked rigidity of the recti muscles, and no cutaneous hyperaesthesia. The stomach was distended with gas, the resulting swelling was confined to the epigastrium, but no peristalsis was seen and no distension of the colon could be made out. The urine was normal; the temperature rose to $100^{\circ} \mathrm{F}$. on one occasion, but was otherwise normal.

$X-r a y$ Examination.-The lowest point of the stomach was situated $2 \frac{1}{2}$ in. below the umbilicus; it emptied rapidly, and in two hours there was a large shadow in the caecum and lower part of the small intestine. A doubtful shadow was seen in the part of the small intestine. A doubtrul shadow was the small intestine. In four hours the caecum was empty and the transverse colon four hours the caecum was empty and the transverse colon which probably ran through the fistula. The stomach did not all up. The examination was thus inconclusive. A faecal istula was diagnosed without further investigation.

\section{Operation (W. T.)}

An incision was made through the left rectus. There were many firm adhesions in the region of the anastomosis and involving the stomach, transverse colon, and spleen. When these had been separated the anterior aspect of the jejunum at the anastomosis was found to be firmly united to the posterior aspect of the transverse colon over an area about $\frac{3}{4} \mathrm{in}$. in diameter. There was obviously a communication between the two organs at this point. The colon and jejunum were now dissected apart, the tistula being thereby opened. It was found possible to separate the two organs freely without encroaching on either unduly. The resulting openings in the colon and jejunum were stitched up, the gastro-jejunostomy being left intact. A temporary caecostomy opening was made through a short incision in the right iliac fossa.

The operation was difficult on account of the adhesions. Although these were separated with great care, a laceration of the spleen was produced, which bled profusely until it was closed by sutures.

\section{Subsequent Course.}

The case ran a normal course and the patient left the hospital In three weeks. For the first ten days he passed a motion each day, which was light coloured as before the operation; then the motions became darker and were practically normal when the patient left the hospital; in fact he required an occasional gaerient. There was no pain or other svmptom. He was seen again in February, 1920, and stated that he had been very well again in February, 1920, and stated that he had been very well antil two months previousty. He then developed pain one hour distension. There had been no yomiting nor diarrhoea. $\mathrm{He}$ now and then experienced the old ulcer pain. His weight was 9 st. $12 \mathrm{lb}$.

CASE II.-Gastro-jejunostomy (January, 1918): Constriction of Jejunum and Second Operation (ten days later): Later Diarrhoea and Intestinal Pains : T'wo Operations for Jejuno-colic Fistula (November, 1918, and Narch, 1919, with Temporary Caecostomy): Recovery.

L. M., male, aged 42, was first seen in October, 1918.

\section{History.}

He began to suffer from "indigestion" at the age of 18 years, and definite dudenal pain commenced five years later. He had recurrent attacks of pain at varying intervals, and was treated by many medical men from this time till January, 1918, when he was operated upon and a posterior gastro-jejunostomy performed. "The stomach was dilated and bypertrophied, and the gall bladder was adherent to a large scarred ulcer extending over the whole of the anterior surface of the duodenum. In addition there had at some time been a small ulcer on its posterior surface. There was considerable induration of the showed traces of old inflammatory trouble." "The patient went showed traces of old inflammatory trouble." The patient went
on well for ten days, and then felt nausea and vomited a considerable quantity of " bile." This recurred a day or two later, and second operation was therefore performed. "The jejunum at the centre of the anastomosis was constricted by a band of adhesions, which passed from the mesocolon to the mesentery of the jejunum. The band was intimately adherent to the intestine and could nat be freed. A longitudinal incision to the intestine and could nat be freed. A longitudinal incision was therefore made through this part, which was then sutured
vertically." Three weeks after the operation a sharp pain occurred under the left ribs, more at the back than the front, but this passed off in a few days, and the patient was sent into the country on March lst, 1918. Towards the end of April he began. to have slight pain in the intestines, particularly low down on the right side, otherwise he was fairly well, and had a very good appetite. Early in May the pain increased, and he suffered from diarrhoea constantly. There was no griping pain or sudden call to defaecate, but the patient could pass a liquid and pale stool two or three times a day. As the diarrhoea in complained of eructations of foul-smelling gas and nausea, but never had any vomiting. On May 12th he suddenly vomited half a large basinful of brown liquid having a bad odour. He half a large basinful of brown liquid having a bad odour. He had his stomach washed out once or twice, and in a few days the nausea and diarrhoea ceased. After this for about six weeks he was considerably better, but the foul flatulence troubled him, and he had some pain. He used to often wash out his stomach in the early morning by drinking a solntion of sodium bicarlonate and making himself vomit; a small amount of dark and bad-smelling fluid came up and pieces of stuff like of dark and bad-smelling fluid came up and pieces of stuff like
brown paint; occasionally at night he used to feel as if the brown paint; occasionally at night he used to feel as if the or more of brown material came up. He increased in weight from $8 \mathrm{st}$. $13 \mathrm{lb}$. to $9 \mathrm{st} .5 \mathrm{lb}$. in.August. The abdominal pain now besan to increase, and he had very bad nights and was kept awake by pain and diarrhoea. The pain was always worse and came on sooner when he was lying down or sitting in a chair, but in the upright position he was much more free from pain. The diarrhoea was practically continuous, and he began to lose weigbt. He had a good appetite and ate a liberal diet! The foul flavour was more frequent, and on several occasions he made himself vomit and brought up a large amount of brown bad-smelling material. He only vomited involuntarily once or twice during the whole period. In addition to the acnte intestinal pain in the lower part of the abdomen he also described pain and distension in the upper part, but the pain seemed to spread over the whole abdomen. An examination of the faeces in September showed them to be acid in reaction. no bile pigments, blood, or mucus were present. The total fats were 38 per cent. Microscopically large numbers of muscle fibres, fat globules, and bacteria were seen.

\section{Present State.}

When he came under observation (October, 1918) he was thin and under his ordinary weight. The pain he complsined of was a severe griping in the region of the caecum and transverse colon, with some pain in the left hypochondrium, and also general distension and pain in the whole abdomen. There were occasional eructations of foul gas. The appetite was excellent. Physical examination revealed nothing of importance.

$A$ test meal was administered and the amount withdrawn was only $1 \mathrm{oz}$., so that the stomach emptied rapidly. It was yellowish in colour but was not foul in smell, and oin analysis showed:

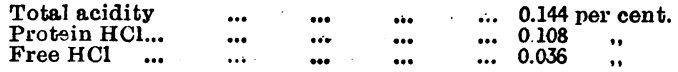

Subsequently four specimens of vomit were obtainsi by the patient making himself sick when he felt his stomach distended.

Specimen 1.-A pint or more of thick brown, semi-fluid material of an obvious faecal odour. 'This was the only occasion on which faecal material was observed.

Specimen 2.-

$$
\begin{array}{llllllll}
\text { Total acidity } & \ldots & \ldots & \ldots & \ldots & 0.365 \text { per cent. } \\
\text { Protein HCl... } & \ldots & \ldots & \ldots & \ldots & 0.146 & , \\
\text { No free HCl } & & & & & & \\
\text { Organic acids } & \ldots & \ldots & \ldots & \ldots & 0.18 & ,
\end{array}
$$

Bile absent. Stercobilin absent. Starch and fat-splitting ferments present in large amounts. There was a large amount of undigested

Specimen 3.-Dirty yellowish in colour, containing a fair amount of undigested food and some flakes of

$$
\begin{aligned}
& \text { Reaction : Acid to phenolphthalein. } \\
& \text { Total acidity } \\
& \text { Acidity due to } \mathrm{HCl}
\end{aligned}
$$

Stercobilin was isolated from the vomit and gave the typical band spectroscopically. Indol was obtained by distillation. The vouit contained a fat and a starch-spliting ferment.

Specimen 4,-The vomit separated into three layers, a lower layer and an upper layer of sof t yellowish-whito pultaceous material, which contained a lot of fat and was quite structureless and completely
digested. Extraction gave evidence of stercobilin. Otherwise like result of specimen 3 .

Examination of the faeces showed them to consist of a liquid brownish-white material, with small hard whitish masses. There was no blood or mucus. Microscopically there was no undigested muscle or vegetable fibre. No free undigested starch. The stool contained 80 per cent. water.

$$
\begin{array}{lllllll}
\text { Total fats, dry weight } & \ldots & \ldots & \ldots & 29.72 & \text { grams per cent. } \\
\text { Fatty acids and soaps } & \ldots & \ldots & \ldots & 2096 & \text {. } \\
\text { Neutral fats ... } & . . & \ldots & \ldots & \ldots & 8.76 & \text {. }
\end{array}
$$

It seemed plain from these results that faeces were intermittently entering the stomach and a jejuno-colic fistulb was diagnosed. The stomach emptied itself quite well affimes, but the regurgitation into it of faeces and duodenal cantents simulated retention of food. It was also clear that the direction of flow was from the colon into the stomach. and not vice versa, 
as fio undigested food or excess of fat was present in the faeces. In spite of the presence of faeces in the stomach the appetite was unimpaired, the secretion of $\mathrm{HCl}$ was what is usually found after a gastro-enterostomy, and there was practically no
vomiting. The passage of the colonic contents along the small intestime no doubt was responsible for the diarrhoea.

An $x$-ray examination of the alimentary caual did not help much. The stomach showed nothing abnormal and emptied through the stoma within two hours, a small quantity passing through the pylorus and duodenum. Five and a half hours after ingestion only a small quantity of the meal was in the lower coils of the ileum, the bulk being in the colon, extending into the ascending part of the organ. The passage through the small intestine was thus abnormally rapid. The whole of the meal had been evacuated after twenty-five hours. An opaque mema flavoured with peppermint was administered. A sliadow was seen to distend the descending colon and splenic flexure was seen to distend the descending colon and splenic flexure
and to pass along the course of the transverse colon. No gas flavour w with peppermint was eructated.

A faint shadow appeared above the level of the transverse colori; but it was not definite enough to lead one to infer that the enema had passed into the stomach. The $x$-ray examination thus merely demonstrated the rapid emptying of the stomach and the great irritability of the intestine.

First Operation, November 28th, 1918 (W. T.)

There were many adhesions and much distortion of the parts. The fistula was in the same position as that described in the previous case, and was opened up by dissecting the colon away from the jejunum. On account of the very severe inanition of the patient, which did not seem to permit of a prolonged operation, the separation of the colon and jejunum was carried only just far enough to define the openings which had contributed to the fistula and allow of them being sutured. Even so the operation had been a prolonged one through the difficulties presented by adhesions.

For the first week or ten days after the operation there was very pronounced distension of the caecum and ascending colon, Which could be felt in the right side of the abdomen as a firni resonant swelling. It was feared at one time that the condition would pass into one of complete obstruction. Gradually, however, it subsided, though for several weeks the caecum remained unduly prominent, and showed visible and palpable peristalsis.

\section{Subsequent Course.}

The patient gradually put on weight and by the end of February, 1919, was able to walk out. He passed three or four light and loose motions a day for a time. An examination of a stool on December 31st, 19i8. Whitish and containing a lot of viscid mucus. Acid to phenolphthalein, the acidity being 0.073 gram per cent. and due to fatty acids. It contained a fair amount of undigested starch and a very little muscle fibie. $B$. col $i$, streptococci, and a fair number of anaërobes were present.

\section{Chemical examination :}

Water 80 per cent.

Total fats $=14.382$ grams per cent. dry weight.

Falty acids $=14.1$, and neutral fats 0282 per cent.

Stercobilin but no bile present. No digestive ferments present.

This looseness was controlled by chalk and Dover's powder, and finally he passed one light coloured solid motion a day. $\mathrm{He}$ had no severe pain as before, but had distension of the gut on and off, giving rise to slight pain. On March 6th, 1919, he vomited up voluntarily a large quantity of material with obvious faecal odour, and it was quite evident that the fistula had become re-established.

\section{Second Operation, March 10th, 1919 (W. T.).}

The difficulties of clefining the parts involved were greater than at the foregoing operation. Doubtless as the result of the prolonged distension of the caecum and ascending colon the affected organs had been displaced far into the left hypochondriac region and had become fixed there. Full definition was, however, at length obtained, and showed that the fistula had re-established itself apparently by the formation of a small abscess between the line of suture in the jejunum and that in the colon. 'There was, moreover, in the jejunum, just below the level of the fistula, a stricture which made it plain that a resection of this segment would be necessary, and a stricture in resection of this segment would be necessary, and a str:cture in bowel to the size of the little finger. A resection of the colon bowel to the size of the little finger. A resection of the colon
was therefore also necessary. The segment of the stomach wall containing the gastro-jejunostomy opening was cut out and the stomach wall closed, thus abolishing the anastomosis. A length of jejunum of three or four inches, including the anastomosis, the fistula, and the stricture, was removed, and the bowel joined end to end. A length of colon about five inches, including the fistula and the stricture, was then removed and the gap closed fistula and the stricture, was then lemoved and the gap closed was made.

\section{Subsequent Course.}

The caecostomy wound closed in a few days. The patient gradually put on flesh and recovered much more quickly than gradually put on flesh and recovered much more quickly than ciftifort, but no pain or trouble with the bowels. He passed the motion a day, which was formed and gradually became datker in colour. At one time he was a little constipated. When seen last, in December, 1919, he was in a good condition, and had no pain, but only slight distension orcasionally.
C.ASE III.-Posterior Gastro-enterostomy (December, 1910) : Constipation and Intestinal Pain for Five Years : then Diarrhoea and Vomiting: Operation for Eejuno-colic Fistula (July, 1916):

Recurrence of Symptoms.

A medical practitioner, aged 49, came under observation on October 25th, 1910.

$\mathrm{He}$ had suffered from indigestion for fifteen years, and for the past seven years pain under the right costal margin, occurring two to three hours after a meal and having all the characters of that due to a duodenal ulcer. There was never any bleeding. He had lost flesh. There was a tender point about the tip of the ninth right rib cartilage. The total HCl secreted was 0.29 per cent., and an $x$-ray examination showed that the stomach was dilated, but emptied itself within four hours. He was treated in bed on a graduated diet, and was much better in every way, but he still had occasional paiu.

\section{Gastro-enterostomy.}

An operation was recommended, and this was performed on December 12th, 1910. A duodenal ulcer was found which had considerably narrowed the duodenum. There were no adhesions to the liver or gall bladder. The stomach was considerably dilated and there was some obliteration of the lesser sac towards the pyloric end of the stomach. Posterior gastroenterostomy was performed, and the day after the operation the patient vomited a considerable quantity of blood.

After-History.

He recoverel and went away to Cornwall, and in February, 1911, wrote that " the least attempt to eat to full satisfaction was always followed by much discomfort." His diet was of the simplest. His pain under the right costal margin had disappeared, and continued absent for four or five years, when it commenced again, but was not so severe or constant as formerly. Soon after the operation the bowels became very constipated, and the patient suffered from colicky pains in the lower part of the abdomen on and off. He would sometimes have three or four attacks in the day, and they often came on two to three hours after food. Till June, 1916, the patient suffered now and then from these pains and constipation, and, in addition, the old pain had also been present for a year or more. At the end of June, 1916, diarrhoea commenced, and one day there was "constant nausea and a horrible taste in the mouth." In the evening of that day he vomited up a large quantity of material with faecal smell and became quite collapsed. The vomiting recurred on several succeeding days, aud a faecal fistula was diagnosed.

Operation for Jejuno-colic Fistula.

Operation on the fifteenth day after the vomiting commenced (W.T.). A fistula similar to that present in the cases already described was found. The transverse colon and jejunum were dissected apart, and the resulting openings were closed by dissected apart, and the resulting openings were closed by
suture. This was effected without encroaching on the anastomosis or unduly limiting the lumen of either of the segments of gut.

Subsequent Course.

The faecal vomiting was at once arrested and the patient' geweral condition, which had been extremely bad at the time of the operation, began to improve forthwith. The patient remained comparatively well till March, 1917, when the old pain remained comparatively well till March, 1917, when the old pain retarned and melaena occurred. In January, 1918, another attack of the old pain occurred, and amounted to a hunger pain, or below the umbilicus, appeared, and was associated with constipation. These pains continued on and off till May, 1918, when melaena recurred. Since this time he has had several attacks of pain.

CASE IV.-Posterior Retro-colic Gastro-jejunostomy (June, 1914) :

Haematemesis followed by Diarilivea: Fiecal Vomiting: Laparotomy (Harch, 1916): Death.

G. I., male, aged 33 years, was first seen on May 7 th, 1914.

\section{Mistory.}

He gave a history of five years' illness. He had a boring pain situated in the abdomen, just above the umbilicus and extending outwards to the sides and round the back; at times it would extend up over the front of the chest and shoulders. It came on one hour after food and wolie him in the night. It had become more constant and continuous for the last two years the only relief being for about four months in the summer There was no vomiting, unless voluntarily induced, when it relieved the pain. There was never any bleeding. He had feeling of fullness, but there twere no eructations. His appetit. was bad ; the bowels were regular. He. had lost flesh, but wat still fairly well nourished. There was no tenderness. The stomach was dilated and a marked splash was obtained, but no visible peristalsis.

A test meal showed :

$$
\begin{aligned}
& \begin{array}{cccccc}
\text { Total acidity } & \ldots & \ldots & \ldots & \ldots & 0.401 \text { per cent. } \\
\text { Free HCl } & \ldots & \ldots & \ldots & \ldots & 0292
\end{array}
\end{aligned}
$$

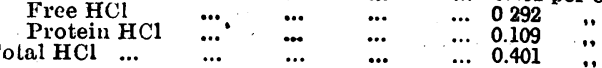

An $x$-ray examination coufirmed the dilatation of the stomach, and showed that the organ emptied itself in four hours. No irregularity suggesting ulcer was seen. 
Posterior Retro-colic Gastro-jejunostomy.

The patient was operated upon in June. The stomach was dilated. A hard mass was situated at the pylorus and fixed posteriorly, the gall bladder being adherent. A posterior retrocolic gastro-jejunostomy was performed.

Symptoms of Jejuno-colic Fistula: Laparotomy; Death.

The patient came under observation again in March, 1916. He had kept well for four months after the operation and then the same pain had started again, and he had vomited blood twice in large quantities. The blood was clotted and coffeecoloured. The pain continued off and on till eight months ago, when it ceased with the onset of diarrhoea. The diarrhoea had continued to the present time. He passed ten or twelve motions a day at the beginning, but at present only three or four. The motions were light in colour. There was a good deal of eructation of wind. The appetite.was poor and the patient was wasted. Vomiting had commenced three weeks before; it occurred one hour after food, and was said to consist of a badsmelling brown liquid. An examination of the vomit showed that it was faecal.

A laparotomy was performed, but the cause of the vomiting was not discovered, and the patient died the next day.

\section{Necropsy.}

The transverse colon was adherent to the stomach and the jejunum, the three being matted together in the region of the gastro-jejunostomy stoma. The stoma was $1 \frac{1}{2}$ in. in diameter and its edges quite smooth. The fistulous opening between the jejunum and the colon was $\frac{3}{4}$ in. in diameter and situated about $\frac{1}{1}$ in. from the stoma; it was lower in level than the stoma and a little to the left of $i t$. There was a stricture of the transverse colon situated at the right edge of the fistula, and the colon was a little dilated behind the stricture The edge of the fistula were quite smooth and healed. This portion of the jejunum was to some extent dilated. (See diagram.)

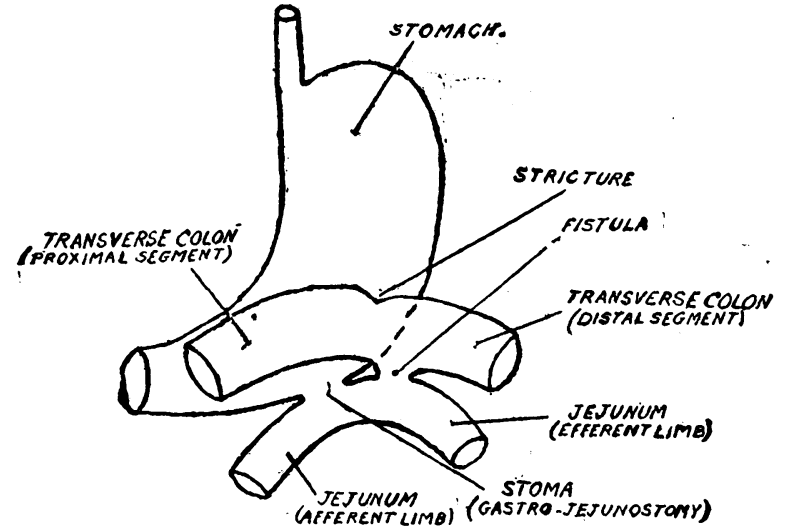

Diagram to illustrate the position of the fistula in Case Iv. (The colon is pulled upwards to expose its junction with the jejunum.)

\section{Pathology.}

The condition present in these cases is nearly always a fistulous communication between the jejunum and the transverse colon, the fistula being situated quite close to gastro-jejunostomy stoma and below it. The colon is situated in front and above the jejunum. This was the condition in our four cases. The descriptions of the exact anatomy of the parts is not always quite clear, but it appears to be uncommon for the stomach itself, through a new aperture or through the stoma, to communicate directly with the colon. Both the stomach and the jejunum may, however, open into the colon in the same case. The fistula may in rare cases be situated a few centimetres lower down the efferent limb. Multiple jejunal ulcers may be present sometimes, and these may eitiver bleed or perforate. The edges of the fistula are smooth and healed, and the gastro-enterostomy stoma may be closed. The ulceration lias probably been more widespread than appear's to be the case, since both closure of the stoma and narrowing of the colon are due to the healing of ulceration. A localized perforation into the anterior abdominal wall may have occurred with the formation of an inflammatory swelling. In most cases, as is evident from a consideration of the anatomy of the parts, the usual result is regurgitation of the contents of the colon into the jejunum, and a mininal passage only of jejunal contents into the colon. "This accounts for the absence of undigested food in the stools in most cases. The degree of regurgitation into the jejunum obviously depends also upon the condition of the contents of the colon; the more liquid they are the more likely are they to regurgitate; and, in fact, at this position in the colon the contents are normally considerably inspissated, hence these patients may only suffer from considerable regurgitation when they have diarrhoea. Thus the regurgitation is intermittent, and the patient feels better when he is constipated. When regurgitation occurs into the jejunum the fluid no doubt passes in considerable quantity down the efferent limb into the small intestine, and in smaller amount into the duodenum and through the stoma into the stomach itself; hence vomiting may be absent or occur at rare interrals only, and the functions of the stomach, both with regard to secretion and motion, be comparatively uninterfered with. The vomit may have different compositions at different times. The circulation of the colonic contents through the small intestine no doubt infects it, and is responsible for keeping up the diarrhoea. Foul gas is more commonly eructated, as the escape of this into the jejunum does not depend on the fluidity of the faeces. How often stricture of the colon results is uncertain, but when it does it is the cause of faecal stasis in the caecum and parts proximal to the fistula, with colic in this portion of the bowel. 'The nutrition of the patient is frequently fairly maintained for a time owing to the absence of vomiting and the retention of appetite, but wasting gradually supervenes, and progresses more or less rapidly. If the stomach directly communicates with the colon-and also sometimes in jejunal fistula-the gastric contents directly pass into the colon, and lienteric diarrhoea supervenes.

\section{Symptomatology.}

The fact that all the recorded cases are of the male sex need cause no surprise when it is remembered that about 80 per cent. of jejunal ulcers occur in men.

The symptoms of fistula may be preceded for a longer or shorter time by those of jejunal ulcer-namely, pain, vomiting, or bleeding, or even those of local peritonitisbut such symptoms may be entirely absent, and the fistula appear to occur in the midst of good health. An unsuspected fistula may be found at an operation undertaken for the relief of recurrent symptoms following gastrojejunostomy.

The time between the performance of the gastrojejunostomy and the development of symptoms of fistula varies from a few weeks to nine and a half years.

\section{Onset.}

Perhaps the earliest symptom in most cases is diarrhoea, usually with intestinal colic, which may begin quite suddenly, and is gradually followed by wasting and occasional vomiting. In a minority of cases the nialady frankly declares itself at once by a sudden and profuse attack of faecal vomiting followed by diarrhoea.

\section{Diarrhoea.}

Diarrhoea does not appear to be as a rule continuous but rather occurs in attacks. It is not a watery diarrhoea, neither are very frequent motions passed as a rule. There is no blood nor mucus separate from the motion. The motion is pale and grumous, and undigested food is usually absent: if a few muscle fibres are found this is rather due to the condition of diarrhoea than to direct passage from the stomach. Neither is the fat usually increased, the proportion of split and neutral fat being about normal. Now and then lienteric diarrhoea is observed and a high percentage of fat. In the intervals formed motions are passed, and at such times the patient appears better in all respects.

\section{Vomiting.}

Although vomiting may be one of the earliest symptoms, and may regularly occur with the diarrhoea, it may be absent or only occasional, or simply induced voluntarily to procure relief. Such cases are very liable to be overlooked, inasmuch as the romited matter may not be available for inspection, and, if it is, it may not be faecu. lent at the time. The vomited matter may be quite similar to that passed by the bowel and have a typical faecal odour, but at other times the vomit simply has a sour smell, and contains bile and pancreatic ferments. "in. such cases the vomit should be examined for stercobilfin and indol due to admixture with small amounts of faecal material. 
Gas.

Eructation of foul-smelling gas appears to be an early and fairly constant symptom, but it would be a mistake to suppose that large quantities of gas are present in the stomach as in some cases of gastro-colic fistula; such is not the case.

\section{Pain.}

Pain of intestinal origin is a symptom of the disease. It is more or less general in distribution, and due to colic of both small and large intestines, but pain below the umbilicus due to colic in the colon is more especially seen and particularly on the right side. It is probable that in such cases there is more or less narrowing of the transverse colon. Two of our cases had a great deal of pain in the left hypochondrium. The pain may be relieved when diarrhoea appears.

\section{Appetite.}

The appetite is often lost, but it is remarkable that sometimes it is quite good and even increased. In one of our cases the patient after vomiting would become quite hungry and eat a good meal. Wasting is a constant symptom, and the patient tends to go slowly downhill.

\section{Physical Examination.}

Nothing characteristic of the disease is revealed by physical examination of the abdomen. There may be some distension, particularly on the right side. Peristalsis of the proximal portion of the colon may be seen. In one case an inflammatory swelling occurred, due to a local perforation of the jejunal ulcer.

\section{Gastric Contents.}

After a test meal the gastric contents show the presence of hydrochloric acid, usually diminished in percentage, as is usual after a gastro-jejunostomy. Free $\mathrm{HCl}$ may be present.

\section{$X-$ ray Examination.}

$X$-ray examination may or may not be of value. In our cases it was inconclusive. In the case of Carnot two examinations were made: at the first the bismuth enema was arrested at the centre of the transverse colon and then passed, little by little, towards the hepatic flexure, whilst at the point of arrest the shadow of the stomach gradually appeared and was separated by an air bubble from the colon. At the second examination there was no gastric reflux to be seen. In the case of Downes the bismuth was seen to pass in both directions. Other observers obtained negative results and others again positive.

Olher Methods of Examination.

Similarly in the case of other methods which have been used for the recognition of gastro-colic fistula, a positive result may or may not occur; such methods as have been employed are:

1. The giving of sabstances by tise mouth which shortly afterwards may be recognized in the faeces (tor example, charcoal or poppy seeds.)

2 . The recovery of a coloured fluid by tubage of the stomach which has been injected as an enema.

3. The direct passage of air into the stomach on insufflation of the rectum, and vice versa.

It is not axtonishing that these methods have yielded different results, when one considers that the cases differ considerably in the exact position and size of the fistula and probably in the fact that the opening may be in some cases valvular.

\section{Diagnosis.}

The diagnosis is made by finding faecal material in the vomit or gastric contents of the patient. This may be very difficult when the leak is intermittent, but when the other symptoms suggest a fistula the attempt should be repeatedly made. If faecal material is present, the only condition likely to be confounded with fistula is intestinal obstruction, which might be suggested by the visible peristalsis which is seen in some cases of fistula, but the persistent diarrhoes and the fact that when constipated the patient is obviously better should prevent confusion. It is so easy to miss these cases that they should always be kept in mind and every case of vomiting and diarrhoen after gastro-jejunostomy thoroughly investigated. The special methods of investigation mentioned above are not likely to prove of value when faecal material is persistentiy absent from the vomit, but when foul gas is eructated and there is no vomiting the stomach contents should be investigated and these methods systematically employed. The presence of lienteric diarrhoea, if it happens, is by na means conclusive, as this may occur in intestinal catarrh.

Prognosis.

The immediate prognosis is good if the case is operated upon. Probably it is alrvays eventually fatal if not operated upon. Of the 31 cases recorded 4 were not operated on and all died, one of perforation of another jejunal ulcer, one of haemorrhage, and two of inanition. Of the 27 cases operated on 21 recovered and 6 died. Of the 6 deaths, in 2 a laparotomy was performed, but the fistula was not touched. Of the cases which recovered, 3 were operated on twice and one three times. The further history of these cases remains to be recorded.

\section{Treatment.}

The only treatment of any avail when a jejuno-colic fistula is established is by operation. The aim should, however, be to prevent the occuirence of jejunal ulcer, which is the cause of the fistula.

\section{Prophylaxis.}

Whether the jejunal ulcer commences at the anastomosis and is the result of the injury inflicted by the operation, or whether it occurs in the jejunum at a distance from the stoma and involves another etiological factor, there is no doubt that the free $\mathrm{HCl}$ of the gastric contents plays the same part during the process of the formation, of the spread, and of the healing of the ulcer, as it does in the case of ulcer of the stomach. The experiments of one of us (C. B. ${ }^{19}$ ) have demonstrated what are the precise effects of this acid at each of the above mentioned stages. The $\mathrm{HCl}$ acts as a protoplasmic poison in strengths such as may be found in the condition of hyperacidity; it possesses irritant properties, and causes gastritis and follicular ulceration; it also possesses necrotic properties, and in strengths which are of themselves inert it can add its devitalizing power to that of another ogent, and thus initiate self-digestion. Thus the formation and spread of an ulcer are greatly facilitated or even initiated, and the healing is delayed owing to necrosis of the connective tissue base of the ulcer, so that the epithelium has no stroma over which to grow.

After the operation of gastro-jejunostomy the percentage of $\mathrm{HCl}$ in the gastric contents is, as shown by Paterson ${ }^{20}$ and Willcox, ${ }^{21}$ diminished, and it is sometimes absent, but several observers have shown that in jejunal ulcer hyperacidity is commonly present, and Paterson, ${ }^{22}$ who strongly supports the importance of this action of $\mathrm{HCl}$, has shown that in such a case the acidity fell on a milk diet, and remained down after operation, but that later, with a recurrence of the pain, liyperacidity again appeared.

The work of Pavlov ${ }^{23}$ has shown that certain foods call forth but little secretion of gastric juice, whilst others produce a maximum secretion. We have thus a method whereby we can control the amount of gastric juice secreted, and if after the operation of gastro-jejunostomy we put these physiological principles into practice, and carefully diet our patients, we shall be doing our best to remove one of the causes of jejunal ulcer. At the same time, the administration of alkalis will materially assist towards this end.

Remarks on Surgical Treatment (W. T.).

It is obvious that the three cases that have come under my care do not afford material for any very wide general conclusions. It would seem that in general the obliteration of the fistula without interference with the gastro-jejunal anastomosis is the best procedure to carry out if it is possible and there is no contraindication such as active úlceration or the presence of a stricture.

To secure satisfactory closure of the openings which have constituted the fistula it is essential that the colon and jejunum should be freely separated from one another, and it is desirable that a piece of omentum should be put between them.

If it is not possible to get the colon and jejunum weH separated without encroaching on the anastemosis, then the latter must be sacrificed and the piece of stomach wall 
containing it excised. If a stricture is actually present or suture of the opening is likely. to narrow too much the lumen of jejunum or colon, an appropriate resection will be necessary.

In any case the establishment of a temporary caecostomy is of the greatest value. The sole purpose of such an opening is to prevent the accumulation of flatus in the colon above the suture line. By it the sutures are relieved from any strain and the patient is entirely.spared the discomfort and danger of post-operative distension.

If the pylorus is still obstructed and it is necessary to obliterate the anastomosis, a fresh gastro-enterostomy must be done or an extensive resection of the stomach, such as described by Clairmont.

\section{REPERENCES.}

1 Czerny : Beit. z. 7klin. Chir.. 39, 1903, Supplement, p. 99. ${ }^{2}$ v. Herczel Cong. de la Soc. Internat. de Chir., Brussels, 1905, p. 350. 8 Knufmaun Mitteil. a. d. Grenzgeb. der Med. und Chir., 19.6, Bd. 15, p. 151. Gosset: Rerue de Chir., 1906. B. 33, S. 59. '5Lion et Moreau : Revice de Chir., 1909, 39, p. 887-891. Grenzgeb. der Med. und Chir., 1907, 13d. 17, S. 590. 7 Paterson : Proc. P. 3, Surgical Section. p. 238. $8 \mathrm{v}$. Roojen Arch. f. klin. Chir., 1910, 91, p. 380. 9 Polya: Deut. Zeit. f. Chirurg. 121, 1913, p. 101. ${ }^{10}$ Hamenn : Trans. Amer. Surgical Assoc., vol. xxxii. 1915, p. 358. "11 Barling: British Journal of Suryery, 1917, v, 343-315, 12 Downes: Anvials of Surgery, 68, July-December, 1918, p. 95 S. 3, xlii, 1173-1180. is Clairmont: Wien. klin. Woch., 1918, xxxi, 285. S. 3, xlii, 1173-1180. 14 Clairmont: Wien. klin. Woch., 1918, xxxi, 285. Arch. de mai. de l'appar. digest., Paris, 1918, ix, 448, 453. 17 Urutia Arch. ce mal. de l'appar. digest., Paris, 1918, ix, 438, 453. 10 Uritia de Mad rid 1911, vi, 361-365, 18 Sherren. After our p3per was writton derion quoted five cases in his Hunterian Lectures in February 1920. 19 Bolton. Gastric : Journ. Path. and Bact., 1915, vol. Xx, p. 133. 20 Paterson of Med., 1909, vol. iii, p. 93. '22 Paterson: Proc. Roy. Soc. Med. vol ii, pt. 3, Surgical Sect., p. $238 .{ }^{23}$ Pavlov: T'he Work of the Digestive Gilands, 1910.

\section{SONE NOTES ON MILITARY OR'THOPAEDICS.} BX

R. W. SUTHERLAND, M.B., Ch.B., MAJOR R.A.M.C.

IATE SURGEON SPECIALIST AND OFFICTR IN CHARGE SURGICAL DIVISION, - MILITARY HOSPITAL

AND

J. M. CHRISTIE, M.B., Ch.B., F.R.C.S.Edin., Captain R.A.M.C.

LATE SURGFON SPECIAIIST AND OFFICER IN CBARGE ORTHOPAEDIO DEPARTMENT, - MILITARY HOSPITAL; SURGICAL SPECIALIST,

IN this article, which is based upon experience gained in the orthopaedic department of a central military hospital we desire to draw attention to certain principles which are not so widely known to the profession generally as they ought to be, and to give some few illustrative details. We do not claim to have made original discoveries, but we have had ample opportunity of applying and learning the value of those made by others, and of working out methods of treatment best suited to the multiplicity of complicated lesions with which we have had to deal.

Our work was under the ultimate supervision of Colonel Carless, C.B.E., A.M.S., Consulting Surgeon to the Eastern Command, whose kindly criticism and unsparing help, and commendation when earned, made it possible.

The accumulation in Eugland of chronic cases showing gross deformity and loss of function, the result of severe gunshot wounds, made it necessary to collect them in centres where they could be studied in detail and collectively, and where treatment could be instituted to restore the maximum function possible.

It was early seen that an authoritative statement of military orthopaedic principles, based on an exact know. ledge of anatomy, physiology, and pathology, was necessary. The principles of treatment were established, and in this matter our country has. been fortunate in possessing as Director of Military Orthopaedics one who has been described in America as the greatest orthopaedic surgeon in the world-Sir Robert Jones.

It was abundantly clear to those of us responsible for surgical cases in military hospitals that no one man cculd carry out satisfactorily the complicated investigation and detailed treatment required. No haphazard method would suffice, but a system must be instituted. Team work in the widest sense was necessary to achieve the best results, with the greatest economy of effort.
Team Work.

Each case was examined by the various men who specialized in some branch of investigation, and when tho notes were completed, with photographs, stereoscopic radiographs, pathologists' reports, reports on electrical examination, results of dental examination, etc., the case was reviewed as a whole. 'The sequence of treatment, operative and otherwise, was considered, with the ultimate result to be hoped for. Each specialist carried out his share, and the head of the department reviewed the cases weekly. The individuals engaged in this work, by exchange of views and discussion of cases, gained a wider knowledge and a broader view than was possible singly. We all felt that by this means we were achieving results which justified our methods.

Those of us who served in the army abroad and had to deal with the severest primary lesions, and who on pension boards are now considering the ultimate results of such cases, are astonished at the wonderful functional recoveries which come before us. When it is remembered that the country has undertaken financial responsibility for these lesions, assessed on the existing degree of disability, it at once becomes apparent how well worth while this work has been to the nation, apart from tho increased productive capacity and happiness of ${ }^{\circ}$ the wounded.

In noting these results it is hardly to be wondered at that Sir Robert Jones, whose principles have formed the foundation of military orthopaedic surgery, wishes to hand on to the civilian population the benefits now conferred on the soldier. The question is a national one, and comparison of expenditure and results to be obtained will show such a plan to be a national economy througli the resulting increase in productive capacity.

In no tield of medicine is the necessity for exact observation and clear thinking so necessary. A limb which at first sight appears hopeless may, as investigation is carried into each detail of its function; finally give a ray of hope; which persistent treatment justifies. Again, have we not of ten heard of useless massage, patiently carried out, for a joint with bony ankylosis? Examplos could be multiplied.

Repair : Principles and Details.

In dealing with chronic sepsis and repair, the questions of phthisis, nephritis, syphilis, dental caries, secondary anaemia, and intestinal toxaemia are of the greatest importance. In the matter of "fresh air" we were able to make an interesting experiment. Our hospital was by the sea. Our surgical wards, built for that purpose, were of brick, large and airy, and we think would have been pronounced excellent by the greatest purist; but we moved our. worst cases to temporary huts by the beach, where their beds could be carried out to the sea front, and where they remained all day. The effect was excellent. As the sun and wind bronzed them, so it seemed their appetites increased, they put on weight, sepsis diminished, and wounds healed. As they watched the bathers in the sea and the children on the beach their whole outlook on life changed, their neurasthenia diminished, and they too were on holiday and wanted to be up and doing again. Employment, amusement, surroundings, fresh air, and sleep-everything helped. The diet was varied and generous, and, when possible, adapted to suit particular tastes.

Anaesthesia.

In the giving of anaesthetics we found a useful field for ether by the rectum, with morphine and atropine. This was specially valuable in head, neck, and chest cases, and in patients who had been gassed or were bronchitic. An enema was given on the day preceding operation; rectal lavage with saline on the morning of operation, and a moderate brealkfast. Morphine gr. $\frac{1}{1}$ with atropine gr. $x^{1} \sigma$ was given, and half an hour later $6 \mathrm{oz}$. of ether to $2 \mathrm{oz}$. of olive oil were very slowly run into the rectum by gravitation; this took twenty minutes to administer. Absolute quiet and suggestion of sleep were employed. When the patient appeared to be sleeping soundly he was carried from the ward to the theatre. Immediately the operation was over a flatus tube was introduced and the anaesthetic evacuated. The rectum was washed out several times with saline, and 2 oz: of pure olive oil introduced. The anaesthesia was light, without post-operative shock, and we had neither sequelae nor complications. 